\title{
Features of tactical and psychological training models in sports climbing at youth level
}

\author{
Antonia Trifu ${ }^{\mathrm{a}}$, Monica Iulia Stănescu ${ }^{\mathrm{a} *}$, Florin Pelin ${ }^{\mathrm{a}}$ \\ ${ }^{a}$ The National University of Physical Education and Sports, 140 Constantin Noica Str., 060057 \\ Bucharest, Romania
}

\begin{abstract}
To enhance the Romanian climbers' performance, an intervention on the tactical and psychological components of the training is needed. We believe that this intervention should be made from a young age. The objective of this paper is to highlight the current training models for sports climbing in the literature and provide a critical analysis on them, so that we can define some project-programmes for the training of young climbers. The systematic review of the literature has identified that the variables most correlated with climbing performance are: mental characteristics (personality traits, temperament, locus of control and tactics), technical characteristics (coordination and technical abilities) and physical characteristics (flexibility, fitness and efficiency). We have also observed how efficient some practical and methodological approaches are in climbing training.
\end{abstract}

Keywords: climbing; tactics; psychological preparation; training; sport

\section{Introduction}

In Sports climbing has grown in popularity in the last decades as a recreational activity, but also as a competitive sport. Improvements in the safety equipment and the construction of many indoor climbing gyms have increased the participation of many women and men of all ages. Also, there is another aspect that increased popularity of competitive climbing, more exactly, the decision of including it to the Olympic Games in 2021. So, coaches around the world are seeking information for various training approaches for raising up their athlete's performance and also for monitoring their progress. Sport climbing is composed of three disciplines: speed climbing, lead climbing and bouldering. Lead climbing is ascending on a route of natural or artificial terrain with preplaced carabiniers, where the athlete has to secure his rope. Bouldering is the discipline where there is no rope needed, the wall is smaller in dimensions and the route is composed of different sequences of moves, which are called cruxes. Speed climbing is a discipline were the climber has to ascent on a standardized climbing wall with special holds. It is considered to be the fastest sport, with records of 5.48 seconds for men and 6.964 seconds for women.

\section{Review of the literature}

\subsection{Youth climber's development}

In Romania, there has been made a study (Trifu, 2020) on the best senior climbers from Romania (national and Balkan champions, the finalists of national competitions) and the researchers concluded that the athletes lack the psychological preparation. They made a study where they analyzed motivation (with its subscales: intrinsic motivation, extrinsic motivation and amotivation), competitive state anxiety, self-

\footnotetext{
* Corresponding author. Tel.: +40-774654101
}

E-mail address: monica_iulia@yahoo.com 
esteem. They conducted the study among 28 climbers from all around Romania and discovered that there was only one athlete who knew how to manage his anxiety and how to control his emotions to transform them into facilitating ones. Also, it is important to highlight that this one athlete wasn't the one with the best performance from the study group. It is important to say that in sports climbing, the difference between seniors and youth it is made at the limit of 16 years old. More exactly, in the IFSC Rules from 2020 it is specified that at a championship, an athlete aged 16 or over can participate along with the seniors and for participation to a Youth World Championship, the athlete can be 19 or under. So, briefly, we can consider that a climber aged over 16 can be called a senior, based on the rules from sports climbing. The competition for youth is based on 3 categories: Youth B (14-15 years old), Youth A (16-17 years old) and Junior (18-19 years old). Mainly, a 16 years old athlete may participate at the youth competition, but also in a senior competition.

We believe that this limit of age may contribute to the best performance results for climbers. Just by observing, at the female category, looking through the Olympic qualified females for Tokyo 2021, 4 out of 17 athletes $(23.52 \%)$ are climbers who had a great performance from their first experience at the world competitions, qualifying to semifinals or finals from the age of 16. Of course, further research is needed in the field of their trainings, how they succeeded this amazing performance, despite their small competitive experience. This finding is in line with recent studies (Corso, 2018) that suggest that among youth athletes there is a lot of potential for improved performance, but there must be direction lines for not destroying the muscular-skeletal system. It is no wonder that the aforementioned example was about women with great performances, because their body develops more rapidly and earlier that boys. Studies have shown that the stature-weight development for girls start at 10-11 years, whereas for boys is at 14-15 years old (Moldoveanu, 2017). Puberty for girls starts at around 11 years and at 13 years for boys. This is why, in climbing, by the age of 16, women are already familiar with their body's changes, their stature grown is on the edge of closing. So, the medical changes about the sex differences regarding puberty tell us that the ending of growing for girls is at 16 years $+/-3$ to 13 months, whereas, at boys the ending of growing is at 17 years and 9 months $+/-10$ months. Obviously, there are individual changes. In climbing, studies (Balas, 2011) have shown that the young elite climbers have similar anthropometric and strength characteristics as adult elite climbers, more exactly: low body fat, high performance in bent-arm hang, grip strength related to body mass and meters climbed per week.

On the other hand, the neuro-psychical maturation starts at the post pubertal stage, so around 15-17 years (Moldoveanu, 2017). The psychological studies have shown that from the age of 12, when the kid enters to the formal operational stage, according to Piajet theory (Huitt, 2003) he can understand and be aware of his performance. But the experimental psychologists suggest that from the age of around 15 (Costa, 1991), with individual changes, the kid can put a finger on what was good, what was bad and what happened to his performance in a competition. Mentally, climbers need to be present in the moment of the ascent, dealing with pressure, displaying resilience and adapting continuously. There is a generalized opinion that young climbers have to train on: focus, analyzing situations, route reading, tactics and they depend on creativity and exploration (LTAD Canadian guideline). Emotionally, the athlete has to control his emotions that arise from success or from failure and has to develop a sense of insight and maturity. This is why, for optimal athlete development, there is a need of training these capacities from as soon as possible. The Canadian guide (LTAD) explains that from the age of 11-15 for girls and 12-16 for boys, the athlete can specialize in one sport by maximizing physical, mental and emotional development and enhance in high type competitions. The authors of this guideline suggested there are 8 stages describing the path of athlete development: the active start (until 6 years old), fundamentals (with accent on the fun part, for 6-8/9 years old), learning how to train (9-11/12 years old). The first three stages emphasize on the general physical development of a child and developing the basic movement and sport skills. The fourth stage of the development is the train to train one (for 11-15 years old for females and 12-16 years old for boys). The fifth stage is about training to compete 
(15-17 years for females and 16-18 for males). It is again, no wonder, that, for climbing, this is the moment where the young athlete can participate alongside adults in competitions. From 18 years old, the athlete learns how to win, then trains for winning (wins for a living) and the last stage is about staying active for life.

All the arguments aforementioned made us believe that there must be used some psychological strategies to enhance senior climbing performance. The field of sport psychology and mental coaching is continuously growing and the need for analyzing the performance with this kind of a specialist is supported by the majority of newer studies.

\subsection{Climbing performance}

The performance in climbing is usually judged by the climber's ability to complete a route of a certain level (grade) of technical difficulty (Magiera, 2013). It is approximately the same for sports climbing, where the climber's objective is also to complete the route from the competition, but his performance is then compared to others' performance.

There have been made some studies which try to identify the climbing variables that enhance performance. Some researchers (Magiera, 2013) concluded that the most significant characteristics are: mental characteristics (personality traits, temperament locus of control and tactics), technical abilities (intersegmental coordination) and physical characteristics (somatic, flexibility, physical fitness and efficiency). These authors found out that $77 \%$ of the performance capacity of the climbers is predicted by: finger strength, mental endurance (from temperament), technique abilities, then isometric endurance of the fingers, oxygen uptake during arm work and ape index. Several studies (Bergua, 2018; Fuss, 2008) suggested that finger strength is one of the best predictors for climbing performance. The anthropometric characteristics that enhance performance in climbing are (Saul, 2019): a low skinfold thickness, a low body fat and large forearm volume. The authors also highlighted the importance of postural stability.

Horst (2003) wrote several popular climbing books and demonstrated that climbing is a unique sport where there are needed mental characteristic, technical and physical abilities. Later on, Horst (2010), proved that many advanced climbers have impressive physical attributes (which they have developed through years of experience), but there is a need for brain development which focuses on: mental agility, intuition, training up weaknesses. The author also highlights that there is a need for a daily mental training and intelligent physical training for unlocking unknown potential of the climber. From another point of view, Guidi (2002) said that the key factors which determine the climber's performance are: mental characteristics (50\%), physical (27\%), tactical $(15 \%)$ and technical characteristics $(8 \%)$.

Reeves (2017) suggested a series of technical, tactical, physical and psychological aspects that need to be improved for rock climbers for a better performance. For tactical preparation suggested that the athlete should: watch others (in order to see the working plan for ascending), control his aggression, have the will to succeed, should improve his concentration, focus, should train his on-sighting skills and red-pointing skills, should find the best places for rest during ascension, should find the suitable situation where he can jump for hold or skip some, should know how to read a route and have an appropriate warm up. About the need for controlling aggression, there have been some contradictions in the literature about this personality trait of the climber: Morgan, Brown, Raglin, O'Connor and Ellickson (1987) suggested that the climber's personality overlaps on the "iceberg profile" where the athlete is low in tension, anger and mood disturbance and high in mental endurance and vigor. Reeves' recommendations are in line with recent studies (Trifu, 2020) which suggested that the tactical preparations mean finding the best places during climbing for securing carabineers, for choosing the best positions for relaxation and releasing arms. In addition, the researchers highlighted the importance of a good visualization. It is essential for the climber to imagine a preview of the route before climbing it. During this, he should identify the places to stop during ascent (as said before), should 
identify the cruxes, and should identify the different types of hold from the route so that he can decide whether to skip or not that hold. About this, there are some studies (Blasing, 2014) that show that perception of the climbing holds activates in the climber's mind some grasping postures, which are not activated in the non-climber community. In other words, when an advanced climber sees a specific hold, he knows the best position of his body he has to adopt in order to maintain his equilibrium. The aforementioned study suggests that the categorization of visually perceived objects, in this case the holds, is influenced by the cognitive-motric memory. This memory depends very much on the observer's experience and expertise. About visualization, Jeannerod (2006) suggest that there are two types of motor simulations: conscious and unconscious one. Pezzulo, Barca, Bocconi and Borghi (2010) suggest that seeing a climbing wall automatically activates specific motor processes in the mind of a climber, which would be supporting the theory of the unconscious visualization. In climbing, the conscious visualization is made voluntarily, as an indeed routine before climbing any route. Furthermore, during a competition, before finals and semifinals, there is a time in the schedule for visualization of the route where the climbers discuss the plan for ascending the route. In addition, as a strategy for ascending, at the immediate time before his ascent, the climber does a quick visualization for incrementing the cognitive-motric skills as a mental simulation for their ascent. Another study (Sanchez, 2012) showed that route preview did influence the climber's performance, more exactly, the athlete did fewer stops on the route (because he didn't need time for planning) and shorter stops (in terms of time) after having a preview. So, a good visualization before the ascent may represent an essential component of performance optimization.

We conclude that visualization is an important tactical practice which stimulates the motric intelligence and motric memory. The visualization is in line with Reeves (2017) recommendations for reading routes.

In addition, we highlight the importance of increasing decisional capacity and creativity, as mentioned in the climbing performance model. The creativity would be the ability of seeing and imaging different ways for approaching the route and imaging different plans for the ascension. To make a comparison, this is like choosing a rote when driving in a crowded city having also a high risk of accidents (Minca, 2013; Tereanu, 2011). This is in correlation with the capacity of adaptation. We believe there is a need for mental adaptation during climbing which can be in relation to the strategy for ascending, another important tactical aspect. The adaptation is referred in the literature (Hill, 2020) as resilience. These researches' study showed that training programs should enhance athletic performance (sports performance) but also their adaptability to stressors (like resilience and antifragility) and by these characteristics, the training programs should be individualized. The resilience it's important because in a competitive sport like sports climbing, athletes constantly interact with stressors and they need to adapt to them. Every route is seen from this point of view as a stressor, as a stimulus to which the climber has to adapt, has to access his motric memory and intelligence to deal with the stimulus (Dragnea, 2006).

The creativity is a characteristic needed for performance in climbing, because it allows the athlete to search for different ways to ascent the route, thus proving his adaptability. It is said (Sudeith, 2009) that indoor climbing walls have a plurality of hand hold that are positioned to provide the climber one or more paths for succeeding the route. In addition, the holds are positioned specifically with respect to each climber for providing a preconceived climbing route.

Another aspect of the tactical preparation is implementing a climbing strategy, especially in bouldering competitions where the athlete can have more than one try on the route. A used strategy would be "the tree tries method", where: the first try is on the first plan that the climber thinks is appropriate. If that try doesn't go well, at the second try he should decide whether he changes the plan or tries on the previous plan but with more strength and concentration. At the third try, he either changes again the plan or goes on the previous try with more strength and concentration and so on. This strategy goes in correlation with an improved decisional capacity where the climber has to decide, from the mattress which plan he adopts. If he doesn't do so, he will lose 
energy during his ascent to find the best route, the best plan and leads to an inefficient style of climbing. Another strategy for visualization (Hurni, 2003) a lead climbing route is the four-read route: the first plan of the route includes identifying all the holds from the ascent, with hands and feet holds. The second plan is a complete visualization from start to top with the entire body imagery. At the third read the climber should observe the holds for relaxing and clipping. The final read means putting all together from the start hold to the final hold, including rests and clips.

So, before the ascent, the climber has to have the capacity of reading the route, so has to make a good visualization of the route and make up in his head some plans for ascending. Furthermore, he has to decide which plan to adopt for the first and maybe the only try. If this plan doesn't work, the climber has to use his creativity to see another plan that can work and decide again if he will use that one. So, we can conclude that the mental capacities that enhance tactical preparation for climbing are all connected to each other.

Horst (2010) highlighted the difference between brain activity which controls the body functions and the mental training which refers to the cognitive, emotional and volitional aspects of a climber. He suggested that the mental training means: increase self-awareness (enhance metacognition and self-coaching for optimizing climber's effectiveness); improve focus, volition and control (using self-talk and anchors); modify behaviours (reducing bad habits and initiating rituals that can enhance performance); manage fears and risk (every climber should learn whether his fears are legitimate or not and also he should learn how to climb at the limit of fear); developing coping skills for difficult situations - for example we can change the way a climber feels about a hard route only by changing his cognition ,this route is difficult" into „this route is challenging”; boost motivation and self-confidence - it is important to sustain an intrisec motivation where the climber wants to be better than his last self which is in correlation with increasing self-confidence; developing intuitive sense - we refer here at the intuition about how to treat a route. By broadening the skills with climbing a lot of routes, the intuition will rise along with creativity and decisional capacity. On the other hand, brain training from his recommendations would mean: accelerating motor skills (developing technical abilities), climbing more on-sight (by broadening skills sets and varying practice, by climbing more on different routes, in different gyms for developing motor programs and motor schema); improve quality of movement (developing the specialized kinesthetic training); developing intuition, developing strength and power, improving the neuromuscular efficiency (by training to balance the strength between muscles and the antagonist muscles in a move for economical movement) and training at the limit of fatigue. About managing fears and risk, studies (Chaloupsky, 2014) showed that climbers usually reach out lower performances (by the route's grade) when climbing on rock routes with a higher level of risk and that the performance is dependent on the risk associated with the climbed route.

\subsection{Performance capacity model}

We (Trifu, 2020) created in 2020 a performance capacity model for climbers which put the accent on all the sides on the training process: psychological, technical, physical, tactical. The most important aspect that starts the climber's potential is his genetics. This virtual potential, when developed thought training, transforms into capacities that enhance performance. The studies (Guilherme, 2014) showed that in a particular sport, the presence of specific polymorphisms may contribute to high levels of performance and several polymorphisms have been associated with athletic phenotypes. The authors concluded that the analysis is more complicated than explaining the performance only bases on genes, but genetics is only one out of many contributing factors to the athletic performance. Studies (Watts, 1993) identified that the performance climbers are small to moderate stature, exhibit low percentage of fat, moderate group strength and body mass ratio, compared to other athletes. This result is in contradiction with the public opinion that elite climbers have a massive muscular development. The physical practice should include general physical preparation and 
specific physical preparation, with respect to developing: arm strength, core strength, finger strength, shoulder strength, leg strength, power (on the superior limb), intersegment coordination, flexibility, cardio-vascular fitness. This is also why climbers around the world would recommend complementary training with swimming, running, fitness training, cycling.

Rock climbers should focus on: high aerobic power, specific muscular strength and endurance. So, they should aim for: overall muscular and cardiorespiratory fitness and specific strength (Kidd, 2009). Other recommendations (Creasey, 2011) for advanced training suggest that there are some physical training principles which come from the age-old cliché that: "the best training for climbing is climbing". Practically, the sport implies the working ability against own weight and against gravity, so a recommendation would be progressive overload of the training program so to avoid burn-out, overtraining and injury (Trifu, 2019).

Also, in the same matter, there is a need for resting well and this also means to prepare the recovery by taking into account the type of training (most climbers need to rest longer after strength training than endurance training). Studies (MacKenzie, 2019) have shown that the most important predictors for maximum climbing are: shoulder power and endurance (measured by maximum pull-ups), average crank power and bent-arm hang, and then, on a secondary plan, grip strength and finger pincer also play a role in prediction.

Other studies (Balas, 2012) explained that hand-arm strength and endurance are predictors for climbing performance, along with climbing experience, volume of climbing, percentage of body fat. The psychological preparation for climbers should go along with the requests from the sports psychology domain (Predoiu, 2016) which support the basic psychological training, specified psychological training and training for competition.

The psychological characteristics that should be enhanced are: competitiveness, determination, happiness, liking challenges, motivation, discipline, positiveness, mindfulness, confidence, coping mechanisms, emotional control, goal setting, imagery, overcoming fear, relaxation, self-belief, self-talk, as Reeves (2017) says.

About the goal setting, there have been many studies (Bull, 2011) which support the difference between a goal centered on the result, a goal centered on the performance and a goal centered on the process. The tactical preparation should include the aforementioned mental capacities that should be improved: visualization, strategy for ascent planning, identifying the best places during ascent (for securing carabiniers, for relaxing, for releasing arms, for finding the best route), creativity and good decisional capacity.

The technical preparation is mentioned to have three components: learning specific basic instructions (like learning how to belay, how to get down from a route, types of ropes, rules about hoe to top a route, what is forbitten and what means that you onsighted a route, learning rules for falling on to the mattress), basic technical training (where the beginner learns the basic technical procedures like: doubling a hold, crimping a hold, using the open hand technique, jumping, running jumps, feet technique, how to footwork, crossing the feet, the variety of holds and their names, knee-bars-ing, how to heel-hook, dynos, the rock-over technique and so on) and specialized kinesthesis training (using deepening the climbing horizons and different exercises on specified holds or boards such as: Metolius, Moon board, campus board).

The most important aspects that need to be improved in the technical field are: balance, coordination, accurate footwork, efficient technique, climbing slabs, corner climbing technique, slab climbing technique, overhanging technique, transferring weight and body position.

A figure of the performance capacity model is presented below (Figure 1): 


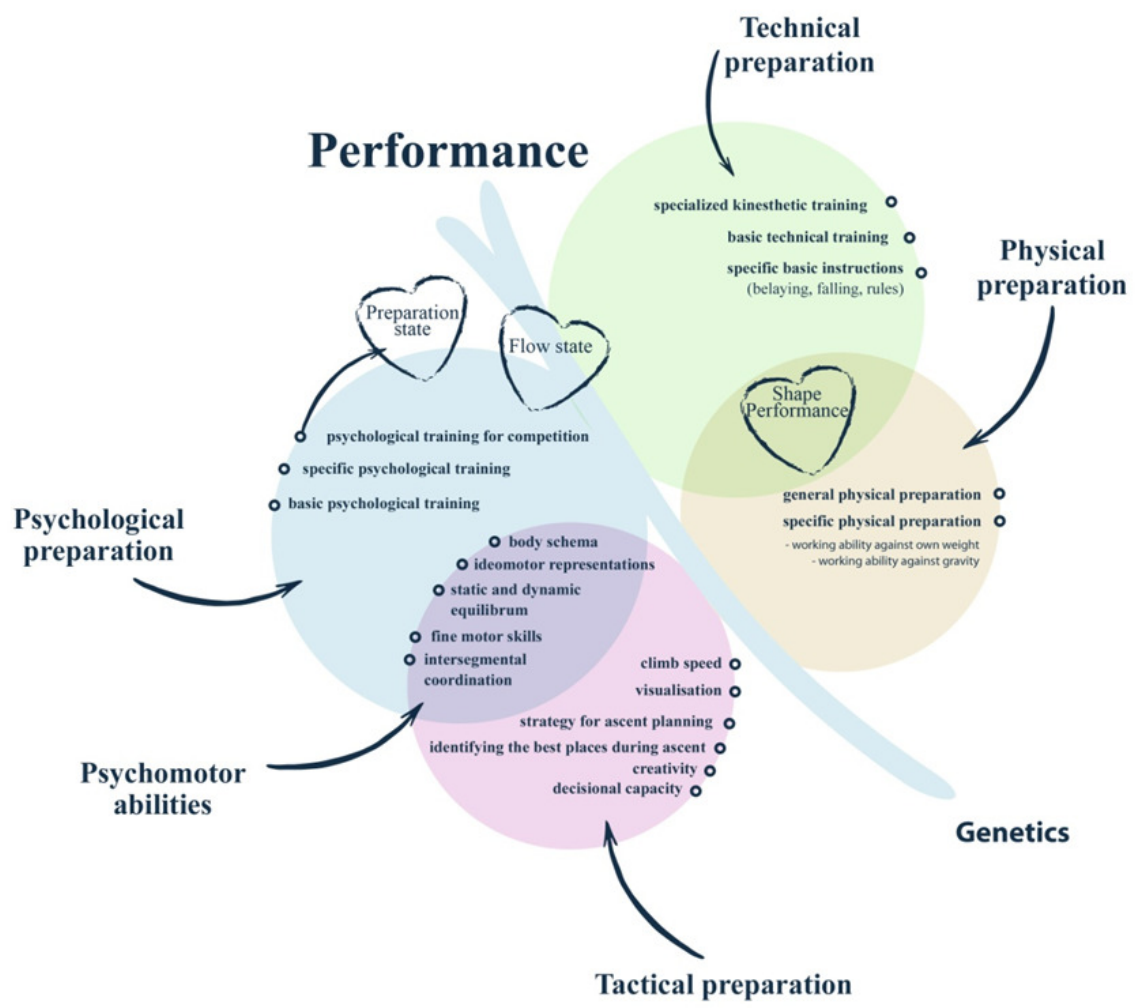

Fig. 1. Performance capacity model

\subsection{Existing practical and methodological approaches in climbing training}

According to advanced training (Shepherd, Banks, Gresham \& Wood, 2011), the authors suggest that a periodized training is needed, using planned training phases like microcycles, mezocycles and macrocycles. They also suggest that there should be an alternation between strength and technical abilities during macrocycles, but the objective is obtaining a peak performance. About the physical training the authors suggest that training sessions should be divided on four levels depending on their intensity and those four types should be scheduled evenly during a week. In their perspective the physical training should be developed after a good mental control and a good climbing technique. Optimizing power and strength is required for executing short, hard crux moves, for bouldering problems. Physical preparation should center around fingers, forearms, upper arms, shoulders, upper back and lower torso. The lower part of the body is more important for problems that are low angled. About specific physical training, the authors highlighted the importance of isotonic strength and isometric strength (holding a hold for a longer period of time). Other guidelines suggest that the climber should vary the handholds (using full crimps, half crims, open hands, sloppers, pinches), the types of moves and the number of moves. Regarding the number of moves, a 2-4 moves route is efficient for maximum strength workout, whereas a 4-8 moves route is efficient for a medium strength workout and a 8-16 moves route trains also the anaerobic endurance. Another type of practical approach for developing strength and power in climbing is improving body tension, because climbers need a great deal of strength in the abdominal and torso muscles. The authors suggest exercises for abdominals, lower back along with footless bouldering and campus boarding. Hurni (2003) suggests that for developing body tension, a good 
exercise would be when the climber grasps a hold, with the arms straight release the feet. The endurance training is divided into anaerobic endurance (for routes about 1530 moves which is the average indoor climbing wall) and aerobic endurance (for single pitch and multipitch climbs). It is recommended for climbers to train at the limit of fatigability, to learn how to tolerate the lactic accumulation. An approach for training anaerobic endurance is the interval training and the type for aerobic endurance is the stick training. This is a practice which simulates the effect of climbing on-sights on a route, the coach pointing the next hold which the climber has to reach.

For developing bouldering skills, Hurni (2003) suggested two kinds of activities: Hour glass pyramid and bouldering pyramid. The Hour glass pyramid is a practice where the climber climbs three easy routes for three times, two medium routes for two times, one hard route for one time and then going back in the same procedure to the easier routes. The bouldering pyramid is a practice where the climber has ten problems with progressing intensity (the first one is the easiest, the tenth one is the hardest). He has to climb the routes in ascending order and then descending to the first route. The same author exemplifies some power endurance practices. An example can be the bad holds activity where the climber has to do one lap on a 25-35 holds route once. For the second lap the coach changes the three best holds from the route into bad holds and repeats the task, and so on. Another practice would be the $4 \times 5$ one where the climber has to do four problems in five minutes, just like in the qualification at bouldering competition where the athlete has to climb for five minutes and then has a break of five minutes. Another practice is pacing the speed of the climber, where the coach counts each foot and hand movement of the athlete. This practice is important for learning climbing with a consistent pace. Another practical approach for developing power endurance is sticking. This exercise will develop climber's quick thinking and on-site ability. The coach has to point the next hold that the athlete has to grasp. The same author recommends the practice of circuit bouldering for developing endurance. The climber has to do as many laps as possible on a boulder problem which starts and ends with the same hold. Another practice is the hold position where each time the athlete reaches for a handhold, he must get into the perfect position for holding it for four seconds. This exercise is helpful for climbers that climb very fast getting out of balance during each move. Another interesting practice is the resting activity, where the climber has a route with some large holds for relaxing. In the resting position the climber has to drop an arm, look at the ground, close his eyes and tell himself to relax and breath. Another practice for developing footwork is climbing a lead route using only small feet holds. When talking about specialized training for competitions, coaches use simulated comps, using sheets for writing down the completed routes, using isolation where the climber is not allowed to watch anyone else on the route he has to climb, using a five minute time for succeeding a route, using a constant number of tries for succeeding a route.

\section{Conclusions}

When we talk about the young climbers that can compete at the adult competitions, in accordance with the LTAD guideline, we are talking about the fifth stage, where the athlete has to learn how to compete. The objectives of this stage include optimizing the periodization of the training, mental, physical, cognitive and emotional development, building self-confidence and increasing competitive performance of the child by competing in higher level of competitions. The physical preparation in this stage should include: individualizes specific physical training, focusing on hand, shoulder, forearm strength and core stability, flexibility training (for the biggest articulations of the body). On the technical preparation, the recommendations are: developing at the highest level the climbing skills, learning competitive skills by training at simulated competitions, developing the personal style. On the tactical preparation, the child should acquire: principles of aggressive and passive tactical strategies, developing the athlete's ability to adapt to different competitive situations and opponents. On the mental preparation, the coach should promote responsibility 
and involvement in decision-making, improving focus and control (using self-talk and verbal cues or anchors), refining goal setting skills, refining imagery skills and coping mechanism for anxiety control and relaxation. The LVAT guideline also suggest some lines for the athlete's lifestyle such as: sport specialization, self-monitoring, plan career or plan if the sport will become the career, promote personal development on all areas, increasing knowledge about the invisible training. It is very important in this period of time to: continue the mastery of various climbing movements and positions on varied terrains (volumes, rock, artificial, different types of holds and so on), learning how to deal with complex sequences, training on combination of power and technical movement, learning visualization and on-sight preparation, do not use additional weight.

Regarding climbing, in every stage of the technical preparation, there is a recommendation for improving quality of movement and deepening experience on specific training, more exactly, broadening the climbing horizons (Horst, 2010). This is why, when having a specialized and careful oriented training, for youth climbers it is not such a big risk for injury, in comparison to other sport disciplines which require more physical development.

There are lots of methodical approaches for developing sports performance in climbing, but, when referring to competitive performance, we should go beyond the physical and technical methods for training. With respect to all the climbers around the world and the recent studies for optimizing maximum climbing, we believe there is a need for developing strategies for increasing the tactical preparation and also mental training along with psychological preparation individually.

\section{References}

1. Baláš, J., Pecha, O., Martin, A. J., Cochrane, D. (2012). Hand-arm strength and endurance as predictors of climbing performance. European Journal of Sport Science, 12(1), 16-25.

2. Balas, J., Vomacko, L., Strejcova, B. (2011). Anthropometric and strength characteristics in young and adult elite climbers. Acta Universitatic Carolinae Kinanthropologica, 47(1), 26-33.

3. Bergua, P., Montero-Marin, J., Bruton, A. G., Casajus, J. A. (2018). Hanging ability in climbing: an approach by finger hangs on adjusted depth edges in advances and elite sport climbers. International Journal of Performance Analysis in Sport, 18(3), 437-450.

4. Blasing, B. E., Guldenpenning, I., Koester, D., Schack, T. (2014). Expertise affects representation structure and categorial activation of grasp postures in climbing. Frontiers in psychology, 5, 1-11.

5. Birren, J. A., Storandt, M., Hulicka, I. M., Baltes, P. B., Costa, P. T., Schaie, K. W. (1991). Psychology and Aging. Nebraska Symposium on Motivation. 39. Lincoln: University of Nebraska Press, pp. 170.

6. Bull, S. J (2011). Psihologia sportului. Ghid pentru optimizarea performanțelor. București: TREI.

7. Chaloupsky, D. (2014). The acceptance level of risk-taking for traditional rock climbers, Journal of human sport \& exercise, 8(1), S263-S269.

8. Corso, M. (2018). Developmental changes in the youth athlete: implications for movement, skills acquisition, performance and injuries. J Can Chiropr Assoc, 62(3), 150-160.

9. Creasey, M., Sheperd, N., Banks, N., Ghesham, N., Wood, R. (2011). The complete rock climber. Hermes House: Wingston.

10. Dragnea, A., Bota, A., Stănescu, M., Teodorescu, S., Șerbănoiu, S., Tudor, V. (2006). Educație fizică și sport. Teorie şi didactică. București: FEST

11. Fuss, F. K., Niegl, G. (2009). Instrumented Climbing Holds and Performance Analysis in Sport Climbing. Sport Technology, 1(6), 301-313.

12. Guidi, O. (2020). Coaching and structure of sport preparation. Available: www.ffme.fr/France.escalade (last accesed on 29.11.)

13. Guilherme, J. P. L. F., Tritto, A. C. C., North, K. N., Lancha, J. A. H., Artioli, G. G .(2014). Genetics and sport performance: current challenges and directions to the future. Revista Brasileira de Educação Física e Esporte, 28(1), 177-193.

14. Hill, Y., Kiefer, A. W., Silva, P. L., et al. (2020). Antifragility in Climbing: Determining Optimal Stress Loads for Athletic Performance Training. Front Psychol, 11, article 272. 
15. Horst, E. J. (2003). How to climb 5.12. Globe Pequot Press.

16. Horst, E. J. (2010). Maximum climbing. Mental training for peak performance and optimal experience. Globe Pequot Press.

17. Huitt, W., Hummel, J. (2003). Piajet's theory of cognitive development. Educational Psychology Interacttive. Valdosta, GA: Valdosta State University.

18. Hurni, M. (2003). Coaching climbing. A complete program for coaching youth climbing for high performance and safety, Falcon: Montana.

19. Jeannerod, M. (2006). Motor cognition. What actions tell the self. Oxford University Press.

20. Kidd, T. W., Hazelrigs, J. (2009). Rock climbing. Wilderness education association, Human Kinetics.

21. MacKenzie, R., Monaghan, L., Masson, R. A., Werner, A. K., Caprez, T. S., Johnston, L., Kemi, O. J. (2019), Physical and Physiologic determinants of rock climbing. International Journal of Sport Physiology and Performance, 14, 1-12.

22. Magiera, A., Roczniok, R., Maszczyk, A., Czuba, M., Kantyka, J., Kurek, P. (2013). The Structure of Performance of a Sport Rock Climber. Journal of Human Kinetics, 36, 107-117.

23. Moldoveanu, A. M. (2017). Dezvoltarea fizică a copiilor. Note de curs, UMF „Carol Davila”

24. Minca, D. G., Furtunescu, F. L., Calinoiu, G., Domnariu, C. D., Costea, R. V. (2013). Profile of persons involved in traffic accidents in Romania. Romanian journal of legal medicine, 21(2), 155-160.

25. Morgan, W. P., Brown, D. R., Raglin, J. S., O'Connor, P. J., Ellickson, K. A. (1987). Psychological monitoring of overtraining and staleness. Br J Sports Med, 21(3), 107-114.

26. Pezzulo, G., Barca, L., Bocconi, A. L., Borghi, A. (2010). When affordances climb into your mind: Advantages of motor simulation in a memory task performed by novice and expert rock climbers. Brain and cognition, 73, 68-73.

27. Predoiu, R. (2016). Psihologia sportului. Maximizarea performanței sportive. Iași: Polirom

28. Sanchez, X., Lambert, P., Jones, G., Llewellyn, D. (2012). Efficacy of pre-ascent climbing route visual inspection in indoor sport climbing. Scandinavian Journal of Medicine and Science in Sports, 22(1), 67-72.

29. Saul, D., Steinmetz, G., Lehmann, W., Schiling, A. F. (2014). Determinants for success in climbing: a systematic review. Journal of Exercise Science \& Fitness, 17, 91-100.

30. Sudeith, T. S., Merlette, J. (2009). US Patent, Everlast Climbing Industries.

31. Tereanu, C., Minca, D. G., Costea, R., Janta, D., Grego, S., Ravera, L., Pezzano, D., Vigano, P. (2011). ExpIR-RO: A Collaborative International Project for Experimenting Voluntary Incident Reporting in the Public Healthcare Sector in Romania. Iranian journal of public health, 40(1), 22-31.

32. Trifu, A., Pelin, F. (2020). Funcționarea intrapsihică a sportivilor de performanță din escalada românească. Unpublished dissertation thesis. UNEFS. Bucharest

33. Trifu, S., Tudor, A., Radulescu, I. (2020). Aggressive behavior in psychiatric patients in relation to hormonal imbalance (Review). Experimental and Therapeutic Medicine, 20(4), 3483-3487.

34. Trifu, S. (2019). Dissociative Identity Disorder. Psychotic functioning and impairment of growing-up processes, Journal of Educational Sciences \& Psychology, 9(71), 102-108.

35. Watts, P. B., Martin, D. T., Durtschi, S. (1993). Anthropometric profiles of elite male and female sport rock climbers. J Sports Sci, 11, 113-117. 